\title{
A prospective study on association of serum uric acid level with knee osteoarthritis
}

\author{
Jain $S^{1}$, Jain $M^{2}$ \\ ${ }^{1}$ Dr Siddharth Jain, P.G. Resident, ${ }^{2}$ Dr Mudit Jain, P.G. Resident, Both are affiliated with Gandhi Medical College \\ Bhopal, MP, India
}

Address for correspondence: Dr Siddharth Jain, Email: dr.sidrjain@gmail.com

\begin{abstract}
Background: A numbers of studies have described a relationship among serum uric acid level and generalized osteoarthritis in recent past, but studies on evidence of relationship among serum uric acid and knee joint osteoarthritis are limited. Present study is intended to validate the association between serum uric acid levels and osteoarthritis of kne joint. Methods: This is a prospective study including three hundred forty patients (225 males, 115 females) with clinically diagnosed osteoarthritis of knee. Patient's radiographs of affected knees and hands were obtained along with their serum uric acid level, Rheumatoid factor and $\mathrm{C}$ reactive protein level. Keligren-Lawrence osteoarthritis scale was used for grading of knee osteoarthritis roentgenographically. On the basis of serum uric acid levels, all the patients were divided in to three groups acoording to serum uric acid level Group 1: - serum uric acid less than 5mg/dl, Group 2: serum uric acid levels between 5.1-7 mg/dl, Group 3: - serum uric acid levels greater than $7 \mathrm{mg} / \mathrm{dl}$. Results: Out of 340 patients, 238 patients (70 \%) dignosed as isolated knee joint osteoarthritis, generalized osteoarthritis is seen in 66 (19.6 $\%)$ patients, and Rheumatoid Factor, along with C-reactive protein is positive in $36(10.5 \%)$ patients. Association of osteoarthritis of knee joint, generalized osteoarthritis with the highest tertile of serum uric acid level found to be strongly positive [adjusted odds ratio- 2.31 and adjusted odds ratio- 3.27 respectively). Also association between increasing serum uric acid levels and progression of the osteoarthritis of knee found to be positive. Conclusion: This study supports a possible correlation between hyperuricemia and osteoarthritis. also a positive association of knee joint osteoarthritis, generalized osteoarthritis progression with increasing uric acid level is suggested.
\end{abstract}

Key words: Osteoarthritis; Serum uric acid, Hyperuricemia

\section{Introduction}

Osteoarthritis is the commonest type of arthritis in orthopaedic practice [1]. The association of osteoarthritis with age, obesity, sex, and metabolic factors has already been established by studies in past [2-7]. Many of these studies showed significant association between osteoarthritis and obesity. Some of the studies on serum uric acid, showed no association between it and osteoarthritis [3-5]. Davis et al found a positive association between knee osteoarthritis and uric acid but association was insignificant [2]. Recently, Kono et al [8] demonstrated that uric acid regulates the inflammation induced by tissue injury, in mouse model. These data form the basis for our hypothesis that

Manuscript received: $07^{\text {th }}$ Feb 2016

Reviewed: $16^{\text {th }}$ Feb 2016

Author Corrected: $25^{\text {th }}$ Feb 2016

Accepted for Publication: 04 ${ }^{\text {th }}$ March 2016 presence of uric acid in synovial fluid dtermines tissue inflammation, disease severity, and progression in osteoarthritis (OA). Acheson et al [9] in their study demonstrated a potive association of serum uric acid level with osteoarthritis of multiple joints. Roddy E, Zhang W et al[10] in their study noted the apparent colocalization of gout attacks and radiographic OA at multiple joints (big toe, ankle, knee, and distal finger joints) and suggested that OA may be developed by the localized deposition of monosodium urate crystals . There is an increasing prevalence of different kinds of arthritis and hyperuricemia worldwide due to increasing use to high caloric diet, higher prevalence of obesity, use of medications like diuretics and intake of fructose in various kinds of beverages [11]. Present study was done to find the association between serum uric acid 
level and osteoarthritis of knee and generalized osteoarthritis.

\section{Materials and Methods}

This study was a prospective study, conducted in Gandhi medical college Bhopal on 340 patients. These patients with complaints of various joints pain attended the department of Orthopaedics from March 2012 to March 2014. Patients included in study, were with age more than forty five years, persistent knee pain more than one month which is insidious in onset and having crepitus during movement of knee joint and roentgenographic evidence of osteoarthritis. In this study patients suffering from knee osteoarthritis of grade 2or more (according to kellgren-lawrence osteoarthritis scale) are included [12].This system has the following grading of knee osteoarthritis:

grade 0: no radiographic features of OA

- grade 1: doubtful joint space narrowing and osteophyte

- grade 2: possible Joint space narrowing definite osteophytes

- grade 3: definite Joint space narrowing,multiple osteophytes possible bony deformity and mild sclerosis

- grade 4: obliterated joint space, large osteophytes, definite bony deformity and severe sclerosis

Generalized osteoarthritis was defined as presence of radiographic changes of osteoarthritis in knee and hand both. In serological testing quantitative fasting serum uric acid, C-reactive protein and Rheumatoid factor were performed. In case of bilateral knee joint involvement, knee with more severe involvement was taken for roentgenographic grading. If both knees have similar symptoms and grading then the radiograph of right knee was included in study. Serum uric acid levels were divided into three groups according to the following distribution of values.

The serum uric acid levels were devided into tertiles.

Group 1:- serum uric acid level less than $5 \mathrm{mg} / \mathrm{dl}$.

Group 2:- serum uric acid level between $5.1 \mathrm{mg} / \mathrm{dl}-7$ $\mathrm{mg} / \mathrm{dl}$.

Group 3:- serum uric acid level greater than $7 \mathrm{mg} / \mathrm{dl}$.

For the evaluation of results and to find any association between various entities patients having knee joint osteoarthritis grade 3 and 4 in each uric acid tertile were compared with the patients in the same tertile of uric acid suffering from grade 2 knee joint oateoarthritis. Patients in the third and second tertile were also compared to first tertile for presence of generalized osteoarthritis and knee osteoarthritis The crude odds ratio (OR) was calculated for the second and third tertiles in comparison to the first tirtle. This was then adjusted for age and sex. Mantel- Haenszel stratified analysis method aw as used for adjustment of odds ratio.

\section{Results}

Out of 340 cases, 225 were males and 115 were females. Knee joint osteoarthritis is present in 238 patients (166 males, and 72 females). Generalized osteoarthritis was seen in 66 patients (43 males, and 23 females). Rheumatoid factor and Creactive protein were positive in 36 patients. Their distribution among the different serum uric acid tertiles is outlined in Table 2.

Table 1: patient distribution according to sex and disease

\begin{tabular}{|l|l|l|l|}
\hline Patients & Total number $(\mathbf{n = 3 4 0})$ & Knee Joint Arthritis $(\mathbf{n = 2 3 8})$ & Generalized Osteoarthritis $(\mathbf{n = 6 6})$ \\
\hline Males & 225 & 166 & 43 \\
\hline Females & 115 & 72 & 23 \\
\hline
\end{tabular}

Association of serum uric acid level with knee osteoarthritis and generalized osteoarthritis was described as odd ratio in table 3 . The crude odds ratio was $>1$ in the association between osteoarthritis of knee, generalized osteoarthritis and the second uric acid tertile $[1.05,1.95]$ respectively.

After adjusting for age and sex parameters, value of odds ratio was found to be significant for the relationship between the second and third tertile of uric acid level and both osteoarthritis of knee and generalized osteoarthritis [odds ratio2.31 odds ratio 3.27 ] respectively. 
Table 2: patient distribution according to Serum uric acid tertiles and radiographic grades of osteoarthritis

\begin{tabular}{|l|l|l|l|l|}
\hline \multirow{2}{*}{ Disease } & \multirow{2}{*}{ Uric Acid Tertiles } & \multicolumn{3}{|l|}{ Kellgren-Lawrence osteoarthritis scale } \\
\cline { 3 - 5 } & & Grade 2 & Grade 3 & Grade 4 \\
\hline \multirow{3}{*}{ Knee Joint Osteoarthritis $(\mathrm{n}=225)$} & $<5 \mathrm{mg} / \mathrm{dl}$ & 35 & 27 & 23 \\
\cline { 2 - 5 } & $5.1-7 \mathrm{mg} / \mathrm{dl}$ & 18 & 22 & 25 \\
\cline { 2 - 5 } & $>7 \mathrm{mg} / \mathrm{dl}$ & 19 & 38 & 31 \\
\hline \multirow{3}{*}{ Generalized Osteoarthritis $(\mathrm{n}=66)$} & $<5 \mathrm{mg} / \mathrm{dl}$ & 10 & 7 & 6 \\
\cline { 2 - 5 } & $5.1-7 \mathrm{mg} / \mathrm{dl}$ & 6 & 7 & 12 \\
\cline { 2 - 5 } & $>7 \mathrm{mg} / \mathrm{dl}$ & 4 & 8 & $\mathbf{1 0 3}$ \\
\hline Total & & $\mathbf{9 2}$ & $\mathbf{1 0 9}$ & 6 \\
\hline
\end{tabular}

Table 3: The relationship of uric acid tertiles with knee and generalized osteoarthritis expressed as odds ratio

\begin{tabular}{|l|l|l|l|}
\hline Disease & Uric acid level & Odds ratio & Adjusted Odds ratio \\
\hline \multirow{2}{*}{$\begin{array}{l}\text { Knee joint } \\
\text { osteoarthritis }\end{array}$} & $<5 \mathrm{mg} / \mathrm{dl}$ & 1.00 (reference) & 1.00 (reference) \\
\cline { 2 - 4 } & $5.1-7 \mathrm{mg} / \mathrm{dl}$ & 1.05 & 1.23 \\
\cline { 2 - 4 } & $>7 \mathrm{mg} / \mathrm{dl}$ & 1.00 & 2.31 \\
\hline \multirow{2}{*}{$\begin{array}{l}\text { Generalized } \\
\text { osteoarthritis }(\mathrm{n}=66)\end{array}$} & $<5 \mathrm{mg} / \mathrm{dl}$ & 1.00 (reference) & 1.00 (reference) \\
\cline { 2 - 4 } & $5.1-7 \mathrm{mg} / \mathrm{dl}$ & 1.95 & 2.26 \\
\cline { 2 - 4 } & $>7 \mathrm{mg} / \mathrm{dl}$ & 1.00 & 3.27 \\
\hline
\end{tabular}

$\mathrm{n}=$ number of patients,

There is a strong association present between osteoarthritis of knee joint, generalized osteoarthritis and the highest tertile of serum uric acid level [adjusted odds ratio - 2.31 and adjusted odds ratio- 3.27 respectively). Also we found a positive association of increasing serum uric acid with progression of the knee joint osteoarthritis (highest tertile in comparison to lowest tertile of serum uric acid odds ratio- 2.07 (table 4).

Table 4: Corelation between serum uric acid tertiles and knee osteoarthritis progression expressed as odds ratio (OR)

\begin{tabular}{|l|l|l|l|l|}
\hline $\begin{array}{l}\text { Serum uric acid } \\
\text { tertiles (mg/dL) }\end{array}$ & $\begin{array}{l}\text { Patients with } \\
\text { grade II knee } \\
\text { osteoarthritis }\end{array}$ & $\begin{array}{l}\text { Patients with grade III } \\
\text { and grade IV knee } \\
\text { osteoarthritis }\end{array}$ & Odds ratio & $\begin{array}{l}\text { Odds ratio adjusted for } \\
\text { age, and sex }\end{array}$ \\
\hline$<5 \mathrm{mg} / \mathrm{dl}$ & 35 & 50 & 1.00 (reference) & 1.00 (reference) \\
\hline $5.1-7 \mathrm{mg} / \mathrm{dl}$ & 18 & 47 & 0.84 & 0.83 \\
\hline$>7 \mathrm{mg} / \mathrm{dl}$ & 19 & 69 & 2.25 & 2.07 \\
\hline
\end{tabular}

\section{Discussion}

In our study epidemiologic results particularly about greater prevalence of hyerurecemia among male are very much comparable with other previous studies This study also showed an association between hyperuricemia and generalized osteoarthritis as described by various previous studies [8,9] This may be explained by the pro-inflammatory effect of the elevated serum uric acid [13]. In a study done by Anna E. Denoblea et al.[14] the strong association of synovial fluid uric acid level with severity of osteoarthritis of knee joint was advocated. In his study he quantified severity of osteoarthritis radiographically and scintigraphically and concluded that uric acid is a marker of disease severity. He also described strong possibility that uric acid may act as a promoting factor in the pathological process of osteoarthritis by activating the cascade of inflammation. Other possible explanatory mechanisms for the association between high serum uric acid levels and knee OA include genetic predisposition, and endogenous hormonal environment. Etiology of osteoarthritis is still doubtful but there are many physiological and clinical factors 
that may contribute to the risk and progression of osteoarthritis. These factors include obesity, joint deformity, trauma, age, and female sex [15].The increase in both hyperuricemia and osteoarthritis in women after menopause indicate towards any possible hormonal mechanisms. Another Indian study by Mishra et al.[16] described correlation of elevated serum uric acid levels with laboratory and anthropometric parameters of various metabolic syndrome. They suggested that this may be due to high caloric diet, sedentary habits and greater prevalence of obesity unfortunately in our study we were unable to find any co-relation in dietary pattern and life style with the elevated serum uric acid level. An co-relation between rise in uric acid level and progression of knee osteoarthritis was also found in present study which is comparable to result of various previous studies $[6,7,15]$. Our study also showed the correlation of serum uric acid level with radiographic severity in knee joint osteoarthritis as measured by Kellgren-Lawrence osteoarthritis scale has been previously reported by Anna E. Denoblea et al [14]. Another reason for the observed association of uric acid level with osteoarthritis of knee joint and generalized osteoarthritis in present study may be that we did not excluded patients already having diabetes and medications including diuretics which have been shown to be associated with osteoarthritis.

\section{Conclusion}

This study supports a possible correlation between hyperuricemia and osteoarthritis. But various confounding factors such as endogenous hormonal environment, insulin resistance, and genetic predisposition exist, to affect the possible association between hyperuricemia and osteoarthritis. To validate this issue a large sample size multifactorial study is recommended.

Funding: Nil,

Conflict of interest: None.

Permission of IRB: Yes

\section{Reference}

1. Klippel J, Dieppe P (eds). Radiology 2nd ed. London: Mosby, 1998, pp. 2, 1-8.

2. Davis MA, Ettinger WH, Neuhaus JM. The role of metabolic factors and blood pressure in the association of obesity with osteoarthritis of the knee. J Rheumatol. 1988 Dec;15(12):1827-32.

3. Felson DT, Anderson JJ, Naimark A, Walker AM, Meenan RF. Obesity and knee osteoarthritis. The Framingham Study. Ann Intern Med. 1988 Jul 1;109(1):18-24.

4. Bagge E, Bjelle A, Edén S, Svanborg A. Factors associated with radiographic osteoarthritis: results from the population study 70-year-old people in Göteborg. J Rheumatol. 1991 Aug;18(8):1218-22.

5. Schouten JS, van den Ouweland FA, Valkenburg HA. A 12 year follow up study in the general population on prognostic factors of cartilage loss in osteoarthritis of the knee. Ann Rheum Dis. 1992 Aug;51(8):932-7.

6. Hart DJ, Spector TD. The relationship of obesity, fat distribution and osteoarthritis in women in the general population: the Chingford Study. J Rheumatol. 1993 Feb;20(2):331-5.

7. Hart DJ, Doyle DV, Spector TD. Association between metabolic factors and knee osteoarthritis in women: the Chingford Study. J Rheumatol. 1995 Jun;22(6):1118-23.

8. Kono H, Chen CJ, Ontiveros F, Rock KL. Uric acid promotes an acute inflammatory response to sterile cell death in mice. J Clin Invest. 2010 Jun;120(6):1939-49. doi: 10.1172/JCI40124. Epub 2010 May 24.

9. Acheson R, Collart AB. New Haven survey of joint diseases XVII: Relationship between some systemic characteristics and osteoarthritis in a general population. Ann Rheum Dis, 1975. 34(5): p. 379-87.

10. Roddy E, Zhang W, Doherty M. Are joints affected by gout also affected by osteoarthritis? Ann Rheum Dis. 2007 Oct;66(10):1374-7. Epub 2007 Feb 6.

11. R N Sarkar, Kuntal Bhattacharyya et al. Gout updated 2012 Medicine Update Vol. 22v: 674-79 DOI: http://dx.doi.org/10.1016/S0973-3698(11)60025-3.

12. Kellgren JH, Lawrence JS. Radiological assessment of osteo-arthrosis. Ann Rheum Dis. 1957 Dec;16(4):494-502. 
13. Ruggiero C, Cherubini A, Ble A, Bos AJ, Maggio M, Dixit VD, Lauretani F, Bandinelli S, Senin U, Ferrucci L. Uric acid and inflammatory markers. Eur Heart J. 2006 May;27(10):1174-81. Epub 2006 Apr 12.

14. Denoble AE, Huffman KM, Stabler TV, Kelly SJ, Hershfield MS, McDaniel GE, Coleman RE, Kraus VB. Uric acid is a danger signal of increasing risk for osteoarthritis through inflammasome activation. Proc
Natl Acad Sci U S A. 2011 Feb 1;108(5):2088-93. doi: 10.1073/pnas.1012743108. Epub 2011 Jan 18.

15. Al-Afraj AS. Serum uric acid and radiographic osteoarthritis. J Pak Med Assoc. 2003; 53(5):187-9.

16. Misra A, Khurana L. Obesity and the metabolic syndrome in developing countries. J Clin Endocrinol Metab. 2008 Nov;93(11 Suppl 1):S9-30. doi: $10.1210 /$ jc.2008-1595.

\section{How to cite this article?}

Jain S , Jain M . A prospective study on association of serum uric acid level with knee osteoarthritis . Int J Med Res Rev 2016;4(3):289-293. doi: 10.17511/ijmrr.2016.i03.01. 